\title{
Developing an understanding of fatal child abuse and neglect: Results from the South African child death review pilot study
}

\author{
S Mathews, ${ }^{1} \mathrm{MPH}, \mathrm{PhD}$; L J Martin, ${ }^{2} \mathrm{MB}$ BCh, Dip For Med (SA), MMed Path (Forens), FCFor Path (SA) \\ ${ }^{1}$ Children's Institute, Faculty of Health Sciences, University of Cape Town, South Africa \\ ${ }^{2}$ Division of Forensic Medicine and Toxicology, Department of Pathology, Faculty of Health Sciences, University of Cape Town, South Africa
}

Corresponding author: S Mathews (shanaaz.mathews@uct.ac.za)

Fatal child abuse is the severest consequence of violence against children. Yet, little is known about this phenomenon, as routine data do not describe it. Child death review (CDR) teams have been established to systematically review deaths from birth to adolescence as a public health response to better identify child abuse deaths, to develop policy and to improve the child protection response. This article describes the incidence of fatal child abuse and injury patterns associated with such deaths. CDR teams reviewed all child fatalities from 1 January to 31 December 2014 at two pilot sites in South Africa (SA). Data were collected on demographics, causes and circumstances of the death, and family social context. We assessed the feasibility of CDR teams in the SA setting to strengthen the identification of child abuse deaths and influence practice. A total of 707 cases were reviewed. Over half (52.4\%) of the deaths were due to natural causes. A third were caused by murder, with nearly half (44\%) of all murders attributed to fatal child abuse. The burden of fatal child abuse and neglect was found among the $<1$-year age group. Abandonment at birth was most common, followed by blunt force injuries and strangulation/asphyxiation deaths. CDR teams are effective in better identifying deaths due to child abuse and neglect via a multidisciplinary approach and regular case reviews.

S Afr Med J 2016;106(12):1160-1163. DOI:10.7196/SAMJ.2016.v106i12.12130

Violence against children is a pervasive problem in South Africa (SA). Yet, there is an absence of routine data sources to monitor the prevalence and incidence of child violence, in particular child abuse and neglect. Fatal child abuse is the most severe consequence and forms a proxy measure for the effectiveness of a country's child protection system. ${ }^{[1]}$ The SA child homicide study estimates a child homicide rate of 5.5/100 000 children $<18$ years of age ${ }^{[2]}$ - more than double the global child homicide rate. ${ }^{[3]}$ Furthermore, the relationship between child homicide and fatal child abuse was noted, with nearly half (44.6\%) of child homicides related to child abuse and neglect. However, child abuse deaths were not always managed within a child protection framework and many of these deaths remain hidden. ${ }^{[4]}$

Underestimating the burden of child maltreatment has been shown in multiple settings, with only a third of these deaths classified as homicide. ${ }^{[5]}$ It is estimated that $13 \%$ of all injury deaths in children $<15$ years old are due to child abuse and neglect. ${ }^{[3]}$ Studies from high-income settings have shown that fatal child abuse is poorly detected in vital statistics, by child protection services, and by the police, resulting in a huge underestimation of fatal child abuse. ${ }^{[5]}$ The poor detection rates of child abuse deaths are primarily owing to difficulties in identifying such deaths, investigating and reporting of such deaths by police to child protection services, and a lack of standard definitions of child maltreatment. ${ }^{[6]}$ Deaths caused by violence or severe physical abuse are more likely recognised as child abuse deaths, ${ }^{[7]}$ while deaths related to neglect/omission of care - including abandonment or those resulting in drowning, poisoning and fire injury - are more likely to remain undetected. ${ }^{[7]}$ Furthermore, deaths in infancy due to asphyxiation from smothering or overlaying (accidental smothering of the child by a larger person lying on them, e.g. in crowded beds) are easily misclassified as sudden infant death syndrome (SIDS), with $10 \%$ of SIDS deaths shown to be infanticide. ${ }^{[8]}$
Child death review (CDR) teams have been implemented in high-income countries to address the poor identification of child maltreatment deaths to develop policy and interventions to prevent such deaths. ${ }^{[9]}$ CDR teams aim to review each child death using a public health framework to identify factors to prevent future child deaths. These CDR processes collate comprehensive data for each child death. Viewed as a sentinel event, each suggests potential modifiable factors to inform recommendations for improvement of the health and child protection system. ${ }^{[10]}$ The efficacy of CDR teams is the result of its multidisciplinary nature, consisting of a forensic pathologist, investigating officer, child protection worker (social worker), prosecutor and paediatrician as the core team who meet regularly to share case-specific information on the circumstances surrounding each child death. ${ }^{[11]}$ Over the last three decades, CDR processes have evolved in high-income countries, with variation across countries, but most have adopted a prospective rapid response approach for all unexpected child deaths to understand the clinical causes and contributing factors. ${ }^{[10]}$

Based on gaps identified by the child homicide study and a review of international practices to manage child deaths, a CDR process was identified as best practice for strengthening responses. ${ }^{[12]}$ This article draws on the SA CDR pilot study to explore its use in improved identification of child abuse- and neglect-related deaths and the implications for practice.

\section{The child death review pilot study -} testing a multi-agency model

A CDR pilot study was initiated in 2014 at Salt River Mortuary, Western Cape, and Phoenix Mortuary, KwaZulu-Natal, SA. CDR teams were established at both pilot sites and all child deaths from 1 January to 31 December 2014 were reviewed. The formation of 
these multi-agency teams was based on services available in the district and the responsibility of agencies to manage child health and child abuse. Development and co-ordination of the teams were key. This process was led by the Children's Institute, University of Cape Town, which facilitated the process of identifying and meeting with relevant government agencies and non-governmental services operating in the two districts. This allowed for buy-in into the concept and identification of core team members from the relevant sectors to participate in the process. Participation by CDR team members was voluntary, but based on the agency mandate to focus on child health or protection.

This pilot study was modelled on the international multiagency approach. ${ }^{[10]}$ It aimed to facilitate a co-ordinated response between police, forensic pathology services, prosecution authorities, paediatricians and social services in the management of all child deaths. Two pilot sites were selected based on an interest from the forensic pathologists, the difference in size of the mortuaries and the diversity of the catchment districts. Forensic pathologists play the lead role in the review process, as they identify the cases presenting to the mortuary on a monthly basis and prepare the cause of death data and the known social circumstances information for the monthly CDR meetings. Confidentiality is key; therefore, all shared information is anonymised. Team members all signed a confidentiality agreement, as most cases are still undergoing legal investigation that should not be compromised through this process. Moreover, families are at the centre of the investigation and distressed by the death of their child.

The CDR sample included all children admitted to the mortuaries in terms of the Regulations (No. R636) to the National Health Act 61 of 2003. ${ }^{[13]}$ This definition of unnatural death includes all sudden and unexpected deaths. Although the CDR pilot study's overarching goal tested the efficacy of CDR teams in the SA setting to identify gaps in health and social services to prevent future child deaths, a particular focus was to improve the identification of fatal child abuse cases. The multi-agency approach promoted a prospective rapid response investigation into suspected child abuse and neglect, as all roleplayers are involved in the case discussion to facilitate an appropriate medicolegal investigation. The review process adopted a social autopsy approach, where the social contributors to a child's death are discussed alongside the medical cause of death. ${ }^{[14]}$

\section{Overview of the CDR process steps}

- Team discussion to clarify all case information: initially the forensic pathologist leads the discussion on the autopsy findings and cause of death.

- Clarify the events that led to the death: forensic officer's report, crime scene investigation report and police investigation report provide the team with a fuller picture to match the forensic examination with the child's death circumstances.

- Identify whether additional information is required: social contributors to the deaths are discussed alongside the medical cause to determine whether further investigation is required.

- Establish whether the death was avoidable: this decision is taken once all the information is brought to the CDR meeting.

- Identify potential preventable or remedial factors: the team decides on further action based on the outcome of the full discussion.

\section{What have we learnt?}

We reviewed 707 cases, with $52.4 \%$ of the deaths due to natural causes (Table 1). This was followed by accidental deaths (25.6\%) and murder $(15.5 \%)$. Deaths in the $<1$-year age group were mainly due to natural causes $(81.7 \%)$, whereas accidents were highest $(71.9 \%)$ in the 5 - 9-year-old group. Murder and suicide were highest among 15 - 17-year-olds.

Table 2 shows type of violence by demographic and murder characteristics. Overall, there were more male (64.8\%) than female (33.1\%) deaths. Over half (60.4\%) of girls were killed in the context of child abuse compared with $33.3 \%$ of males. Neglect-related deaths were more common among males (60.1\%) than females (39.4\%). Non-abuse murders mainly occurred in males (91.8\%). Most (60.4\%) child abuse-related deaths occurred in the $<1$-year age group. Similarly, neglect-related deaths were most common in the $<1$-year age group $(60.1 \%)$, followed by the $1-4$-year age group $(27.7 \%)$. Older boys in the $15-17$-year age group were most likely $(83.6 \%)$ to be victims of non-abuse-related murder. Overall, most children were killed in public spaces $(47.2 \%)$ or the victim's home $(33.8 \%)$. Child abuse (40.4\%) and neglect deaths (72.7\%) were more likely to occur at home than non-abuse murder $(74.2 \%)$ in public spaces.

Gunshots (22.5\%) and stab wounds (21.8\%) were the most common causes of death in non-abuse murders. Abandonment at birth was the most common cause of abuse- and neglect-related deaths (37.5\%), followed by blunt force injury (14.6\%) and strangulation/ asphyxiation (14.6\%) deaths. There were 8 cases of rape homicide of girl children; 1 each in the 1 - 4-year and 5 -9-year age groups; and 3 each in the 10 - 14-year and 15 - 17-year age groups (data not presented). Lower-respiratory tract infection was most common (39.4\%) in neglect-related deaths.

\section{What are the implications for practice?}

The CDR process reviews all cases of child deaths admitted to the Forensic Pathology Service (FPS). The regulations define unnatural death (requiring referral to the FPS) as any death due to physical or chemical influence, direct or indirect, or related complications; any death, including those which would normally be considered to be due to natural causes, which in the opinion of a medical practitioner, has been the result of an act of commission or omission, which may be criminal in nature; and where the death is sudden and unexpected, or unexplained, or where the cause of death is not apparent. ${ }^{[13]}$ It is suspected that not all sudden, unexpected or unexplained deaths are referred to the FPS. This could account for the difference seen in our results between the two sites in terms of the numbers of 'natural' cases admitted (Salt River $-60.6 \%$, Phoenix $-27.6 \%$ ), ${ }^{[15]}$ which were mainly in the younger age groups. Most cases admitted under the category of sudden, unexplained and unexpected are reclassified into natural cases on postmortem examination. The extent of the postmortem examination is at the discretion of the examining forensic practitioner following national guidelines, and may not include a full autopsy. However, in such cases, especially in the younger age groups, a concealed homicide or accidental overlaying may be missed by a clinician who completes a death notification form as a natural cause of death without referring the case to the FPS for further investigation. This has been highlighted previously, where infant deaths caused by asphyxiation from smothering or overlaying are potentially misclassified and remain undetected. ${ }^{[7,8]}$

The importance of referrals of sudden unexpected death in infants (SUDI) and interconnections with possible omission of care or neglect by a caregiver were highlighted by the CDR pilot study. We referred 50 SUDI cases for further investigation and support to the Department of Social Services to investigate the social circumstances, in particular the care that children received before their death; 33 cases were confirmed as neglect. In one case an 8-month-old baby presented at the mortuary as a SUDI. At autopsy the cause of death was gastro- 
Table 1. Proportion of child deaths by age and manner of death

\begin{tabular}{|c|c|c|c|c|c|c|}
\hline Manner of death & $\begin{array}{l}<1 \text { year } \\
(n=374), \%\end{array}$ & $\begin{array}{l}1 \text { - } 4 \text { years } \\
(n=105), \%\end{array}$ & $\begin{array}{l}5 \text { - } 9 \text { years } \\
(n=57), \%\end{array}$ & $\begin{array}{l}10-14 \text { years } \\
(n=63), \%\end{array}$ & $\begin{array}{l}15-17 \text { years } \\
(n=108), \%\end{array}$ & $\begin{array}{l}\text { Total } \\
(N=707), \%\end{array}$ \\
\hline Accidental & 6.0 & 53.9 & 71.9 & 54.0 & 26.9 & 25.6 \\
\hline Murder* & 7.1 & 6.7 & 3.5 & 23.8 & 52.8 & 15.5 \\
\hline Natural & 81.7 & 37.5 & 19.3 & 11.1 & 6.5 & 52.4 \\
\hline Suicide & 0.0 & 0.0 & 3.5 & 9.5 & 12.0 & 3.0 \\
\hline Undetermined & 5.9 & 3.8 & 3.3 & 1.8 & 1.9 & 4.5 \\
\hline
\end{tabular}

Table 2. Type of violence v. children by category

\begin{tabular}{|c|c|c|c|c|}
\hline Category & $\begin{array}{l}\text { Child abuse-related } \\
\text { murder }(n=48)\end{array}$ & $\begin{array}{l}\text { Neglect-related } \\
\text { deaths }(n=33)\end{array}$ & $\begin{array}{l}\text { Non-abuse-related } \\
\text { murder }(n=61)\end{array}$ & Total $(N=142)$ \\
\hline \multicolumn{5}{|l|}{ Gender (\%) } \\
\hline Male & 33.3 & 60.1 & 91.8 & 64.8 \\
\hline Female & 60.4 & 39.4 & 8.2 & 33.1 \\
\hline Unknown & 6.3 & 0.0 & 0.0 & 2.1 \\
\hline \multicolumn{5}{|l|}{ Age (years), \% } \\
\hline$<1$ & 60.4 & 60.1 & 0.0 & 34.5 \\
\hline $1-4$ & 10.4 & 27.7 & 1.6 & 10.6 \\
\hline $5-9$ & 4.2 & 9.1 & 0.0 & 3.5 \\
\hline $10-14$ & 12.5 & 3.0 & 14.8 & 11.3 \\
\hline $15-17$ & 12.5 & 0.0 & 83.6 & 40.1 \\
\hline \multicolumn{5}{|l|}{ Scene of death (\%) } \\
\hline Home & 40.4 & 72.7 & 8.1 & 33.8 \\
\hline Other home & 4.3 & 3.0 & 9.7 & 6.3 \\
\hline Public space & 38.3 & 9.1 & 74.2 & 47.2 \\
\hline Hospital/clinic & 12.8 & 15.2 & 4.8 & 9.9 \\
\hline Place unknown & 4.3 & 0.0 & 3.2 & 2.8 \\
\hline \multicolumn{5}{|l|}{ Cause of death $(n)$} \\
\hline Blunt force & 14.6 & 0.0 & 6.6 & 7.8 \\
\hline Burns & 2.1 & 6.1 & 0.0 & 2.1 \\
\hline Abandonment/concealment & 37.5 & 0.0 & 0.0 & 12.7 \\
\hline Diarrhoeal disease & 0.0 & 9.1 & 0.0 & 2.1 \\
\hline Drowning & 4.2 & 3.0 & 0.0 & 2.1 \\
\hline Lower-respiratory tract infection & 0.0 & 39.4 & 0.0 & 9.6 \\
\hline Malnutrition & 0.0 & 6.1 & 0.0 & 1.4 \\
\hline Multiple injuries & 10.4 & 0.0 & 0.0 & 3.5 \\
\hline Poisoning & 4.2 & 0.0 & 0.0 & 1.4 \\
\hline Road traffic accident & 0.0 & 6.1 & 0.0 & 1.4 \\
\hline Septicaemia/infection & 0.0 & 9.1 & 0.0 & 2.1 \\
\hline Gunshot & 4.2 & 0.0 & 49.2 & 22.5 \\
\hline Stab & 8.3 & 0.0 & 44.3 & 21.8 \\
\hline Strangulation/asphyxiation & 14.6 & 0.0 & 0.0 & 4.93 \\
\hline Train accident & 0.0 & 3.0 & 0.0 & 0.7 \\
\hline Undetermined & 0.0 & 18.2 & 0.0 & 4.2 \\
\hline
\end{tabular}

enteritis and severe dehydration in a child with features of fetal alcohol syndrome, who was underweight for age. The CDR process revealed that the child had not been attended to at the local child health clinic for immunisation and no medical assistance was sought prior to his death, although he was ill for a few days. Based on these indicators of possible neglect, the case was referred to the child protection agency (CPA) for an investigation into the child's home circumstances. This investigation revealed referral to the CPA for the mother's alcohol abuse and questionable care of her children 6 years previously. It was established that two other child deaths occurred during the CPA's 'care'. The two remaining children were removed from the mother by means of a children's court enquiry.

This case highlights the need to adopt a multi-agency approach to information gathering and response to prevent further deaths of children. Critically, the forensic pathologist reports suspected nonaccidental injury deaths to the police by completing Form 22, which serves as a reporting form to the Department of Social Development. The Children's Act No. 38 of 2005 obliges medical practitioners to 
report suspected abuse (or a reasonable suspicion of abuse or neglect) by completing Form 22 when the child is admitted to a health facility and submitting it to the Department of Social Development or a designated child protection organisation. ${ }^{[16]}$ The CDR team discussion facilitated a process that allowed team decisions to be made regarding suspected fatal abuse and neglect, thereby providing the clinician with a support system to deliberate difficult cases and relieve the burden of making such decisions alone.

Another apparent difference in practice between the two sites highlighted by this study, and noted in a previous study, ${ }^{[17]}$ is the performance of a full v. a partial v. no autopsy in infants. Salt River Mortuary admitted 322 infants, where $48.8 \%$ underwent a full or partial autopsy, whereas Phoenix Mortuary admitted 52 infants, $98 \%$ of whom underwent a full or partial autopsy. The volume of cases admitted, the availability of a good history, and the routine availability of a Lodox Xmplar-dr X-ray system (Lodox, SA) at the Salt River Mortuary may account for the difference in practice. This difference may raise concerns at the possible over- or underdiagnosing of deaths owing to lower-respiratory tract infection in infants, but the high proportion of deaths due to lower-respiratory tract infection is consistent with international reports. ${ }^{[17]}$

\section{Discussion}

The pattern of child abuse-related deaths in this study is similar to that reported by the national child homicide study. ${ }^{[2]}$ Child abuseand neglect-related deaths were most common in the under-5 age group, but the CDR pilot study identified an increase in the number of neglect-related deaths. ${ }^{[2]}$ The CDR process, through its detailed inquiry into the social contributors alongside the medical cause of death, allowed for more accurate identification of contributing circumstances. We have shown that the multi-agency approach to the review of child deaths facilitates a comprehensive process of enquiry by means of a review of biological and social factors and service delivery elements. ${ }^{[18]}$ The cause of death (biological factor) on its own in a SUDI cannot provide the full picture of the circumstances leading to the death. The road-to-health chart, supporting health data and information about the social circumstances provide an enhanced understanding of the context in which children are dying in SA.

The variance in referral patterns at the two sites regarding 'natural' cases is worrying, and awareness needs to be created with medical colleagues and communities of the definition of an unnatural death, specifically the sudden, unexpected and unexplained deaths that must be referred to the FPS for medicolegal investigation. This practice may extend beyond the two sites and be a provincial occurrence, as the referral of sudden, unexpected and unexplained deaths to all the facilities in the Western Cape in this age group is fairly consistent. A concern is the potential for child homicides, in particular neglect-related deaths, to remain undetected and result in further deaths.

The pattern of child abuse-related deaths reveals the high rate of fatal child abuse, particularly among infants. The rate of infanticide in SA is estimated to be among the highest reported rates globally, at 28.4/100 000 live births,${ }^{[1]}$ only surpassing a reported rate for Dar es Salaam, Tanzania. ${ }^{[19]}$ Abandonment and injury deaths of infants were found to be common immediately after birth. This suggests a large number of unwanted pregnancies, which is surprising in a country where contraception is readily available and termination of pregnancy should be accessible during the first trimester. This points to the need for reproductive health services to integrate a mental health component (and vice versa) to identify at-risk mothers perinatally for the provision of support services and home-visiting programmes to reduce the risk of such deaths.

The levels of child abuse- and neglect-related deaths found in this pilot study reflect the endemic nature of child maltreatment in SA, with fatal child abuse conceptualised as the extreme part of the continuum of violence against children. ${ }^{[1]}$ The first national prevalence study on child abuse confirms excessive rates of child maltreatment, with one-third of children reporting experiences of sexual and/or physical abuse during childhood. ${ }^{[20]}$ The insidious nature of violence against children highlights the need to prioritise prevention efforts to break the cycle of child maltreatment, particularly in the home. We have to initiate innovating approaches to prevention by exploring what is effective in similar settings to start shifting the pattern of violence against children.

1. Abrahams N, Mathews S, Martin LJ, Lombard C, Nannan N, Jewkes R. Gender differences in homicide of neonates, infants, and children under $5 \mathrm{y}$ in South Africa: Results from the Cross-Sectional 2009 National Child Homicide Study. PLoS Med 2016;13(4):e1002003. http://dx.doi.org/10.1371/journal. pmed.100200321

2. Mathews S, Abrahams N, Jewkes R, Martin LJ, Lombard C. The epidemiology of child homicides in South Africa. Bull World Health Organ 2013;91(8):562-568. http://dx.doi.org/10.2471/BLT.12.117036 Pinhiero P. World Report on Violence against Children. Geneva: United Nations, 2006.

4. Mathews S, Abrahams N, Jewkes R, Martin LJ. Underreporting child abuse deaths: Experiences from a national study on child homicide. S Afr Med J 2013;103(30:132-133. http://dx.doi.org/10.7196/SAMJ.6724 national study on child homicide. S Afr Med J 2013;103(30:132-133. http://dx.doi.org/10.7196/SAM).6724 Gilbert R, Widom CS, Browne K, Fergusson D, Webb E, Janson S. Burden and consequences of child S0140-6736(08)61706-7

6. Schnitzer PG, Covington TM, Wirtz SJ, Verhoek-Oftedahl W, Palusci VJ. Public health surveillance of fatal child maltreatment: Analysis of 3 state programs. Am J Public Health 2008;98(2):296-303. http:// dx doing

7. Cx.doi.org/ $10.2105 / \mathrm{A} / \mathrm{PH} .2006 .087783$ (r) Crume TL, DiGuiseppi C, Byers T, Sirotnak AP, Garrett CJ. Underascertainment of child maltreatment
fatalities by death certificates, $1990-1998$. Pediatrics 2002;110(2)::18. http://dx.doi.org/10.1542/ fatalities by de

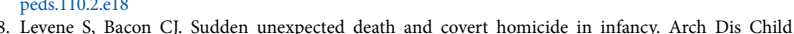
2004;89:443-447. http://dx.doi.org/10.1136/adc.2003.036202

2004,89.443-447. Ctip://dx.doi.org/10.1136/ac.2003.036202 Shanley JR, Risch EC, Bonner BL. US Child Death Review Programs. Am J Prev Med 2010;39(6):522528. http://dx.doi.org/10.1016/j.amepre.2010.08.010

10. Fraser J, Sidebotham P, Frederick J, Covington T, Mitchell EA. Learning from child death review in the USA, England, Australia, and New Zealand. Lancet 2014;384(9946):894-903. http://dx.doi. org/10.1016/S0140-6736(13)61089-2

11. Christian CW, Sege RD. Child fatality review. Pediatrics 2010;126(3):592-596. http://dx.doi. $\mathrm{org} / 10.1542 /$ peds.2010-2006

12. Mathews S, Abrahams N, Martin LJ. Child Deaths Reviews in the Context of Child Abuse Fatalities Learning from International Practice. Cape Town: Children's Institute, University of Cape Town, 2013.

13. South Africa. National Health Act of 2003. Regulations: Rendering of forensic pathology services. Government Gazette No. 30075, 2007. (Published under Government Notice R636.)

14. Kalter HD, Salgado R, Babille M, Koffi AK, Black RE. Social autopsy for maternal and child deaths: A comprehensive literature review to examine the concept and the development of the method. Popul Health Metr 2011;9:45. http://dx.doi.org/10.1186/1478-7954-9-45

15. Mathews S, Martin LJ, Coetzee D, et al. The South African child death review pilot: A multi-agency approach to strengthen healthcare and protection for children. S Afr Med J 2016;106(9):895-889. http:// dx.doi.org/10.7196/SAMJ.2016.v106i9.1123

16. South Africa. Children's Act No. 38 of 2005

17. Groenewald P. Bradshaw D, Neethling I, et al. Linking mortuary data improves vital statistics on cause of death of children under five years in the Western Cape Province of South Africa. Trop Med Int Health 2016;21(1):114-121.

18. Sidebotham P, Fraser J, Covington T, et al. Understanding why children die in high-income countries. Lancet 2014;384(9946):915-927. http://dx.doi.org/10.1111/tmi.12624

19. Outwater AH, Mgaya E, Campbell JC, Becker S, Kinabo L, Menick DM. Homicide of children in Dar es Salaam, Tanzania. East Afr J Public Health 2010;7(4):345-349. http://dx.doi.org/10.4314/eajph. V774.64758

20. Burton P, Ward C, Artz L, Leoschut L. The Optimus Study on Child Abuse, Violence and Neglect in South Africa. Cape Town: UBS Optimus Foundation, 2015. 